\title{
Mujeres artistas de la vanguardia internacional: el caso de Abstraction-Création (1931-1936)
}

\section{Women artists of the international avant-garde: the case of Abstraction-Création (1931-1936)}

\author{
M. LluIISA FAXEDAs-Brujats \\ Universitat de Girona. \\ mlluisa.faxedas@udg.edu
}

Recibido: 3 de septiembre de 2014

Aprobado: 21 de enero de 2015

\begin{abstract}
Resumen
La contribución de las mujeres al arte abstracto del periodo de entreguerras ha sido una cuestión hasta ahora muy poco estudiada. Este artículo trata un tema inédito, el de la participación de las mujeres artistas en Abstraction-Création, la principal agrupación internacional dedicada al arte abstracto de los años 30. Fundado en París en 1931, el grupo recogió el testigo de sendos colectivos anteriores para convertirse en una plataforma de difusión y promoción del arte abstracto. Estaba formado por un centenar de miembros de los que doce fueron mujeres que publicaron sus textos y obras en la revista, abstraction creátion art non figuratif (1932-1936), y participaron en algunas de las exposiciones. En comparación con lo sucedido en grupos anteriores la participación de las mujeres, aunque reducida, fue comparable a la de los hombres, y el impacto de su pertenencia al grupo en sus carreras fue globalmente positivo. Sin embargo, todo ello se dio a costa de renunciar a cualquier especificidad de género en su trabajo y en su presentación pública, y demuestra que la normalización de las aportaciones de las mujeres a las vanguardias sólo pudo darse en paralelo al cuestionamiento de la visión más dogmática de la modernidad.
\end{abstract}

Palabras clave: arte abstracto, mujeres artistas, Abstraction-Création, modernidad, Cercle et carré.

Faxedas-Brujats, M. L. (2015): Mujeres artistas de la vanguardia internacional: el caso de AbstractionCréation (1931-1936). Arte, Individuo y Sociedad, 27(3) 483-501

\begin{abstract}
Women's contribution to abstract art in the interwar period is a subject that, to date, has received very little attention. In this article we deal with the untold story of the participation of women artists in Abstraction-Création, the foremost international group dedicated to abstract art in the 1930s. Founded in Paris in 1931, the group took on the work of two previous collectives to become a platform for the dissemination and promotion of abstract art and consisted of around a hundred members. Twelve of these were women, whose writings and works were published in the group's annual magazine, abstraction creátion art non figuratif (1932-1936), and who participated in a number of the group's exhibitions. Compared to what had occurred in previous groups, the participation of women, although reduced in number, was comparable to that of the male artists and being members of the group had a generally positive impact on the women's careers. However, all this came at the expense of relinquishing any gender specificity in their work and the public presentation of it, and demonstrates that the normalization of women's contributions to the avantgarde could only be brought about alongside a questioning of the more dogmatic views of modernity. Keywords: abstract art, women artists, Abstraction-Création, modernity, Cercle et carré.
\end{abstract}


Sumario: 1. Introducción, 2. La abstracción en los años 30: de Art concret y Cercle et carré a Abstraction-Création, 3. Las mujeres artistas de Abstraction-Création, 4. La revista abstraction création art non figuratif (1932-1936), 5. La participación de las mujeres artistas en la revista, 6. Después de Abstraction-Création, 7. Conclusiones. Referencias.

Este artículo recoge resultados de la investigación "La cuestión del archivo en las prácticas artísticas y museísticas contemporáneas" financiada por el Ministerio de Ciencia e Innovación (ref: HAR201127839).

\section{Introducción}

La incorporación de las mujeres creadoras a las vanguardias artísticas del periodo de entreguerras es un hecho que en algunos de sus aspectos más importantes ha sido ya ampliamente documentado; así, por ejemplo, existe un número muy importante de publicaciones sobre las mujeres artistas del Surrealismo (Chadwick, 1985; Rosemont, 1998), pero han sido también estudiadas las mujeres de Dadá (Hemus, 2009), las participantes en la llamada Escuela de París (Perry, 1995) e incluso las integrantes de la más conservadora Société des Femmes Artistes Modernes, conocida como FAM (Birnbaum, 2011). Existe también bibliografía sobre las mujeres próximas a la abstracción en los círculos de la Bauhaus (Baumhof, 1999; Müller, 2009) y de las vanguardias rusas (Bowlt y Drutt, 2000). En comparación, sin embargo, la bibliografía sobre las mujeres que tomaron parte en las diversas tendencias de la abstracción localizadas en París es muy escasa (Wismer, 1995; Gonnard y Lebovici, 2007). Aunque sin duda representaron un grupo cuantitativamente numeroso, y cualitativamente muy interesante, diversas y complejas razones explican el escaso interés por las mujeres de la abstracción, tanto por parte de la historiografía tradicional como desde puntos de vista más contemporáneos (Faxedas, 2013). Este artículo se centra en las mujeres que participaron en el grupo de artistas abstractos más importante de los años 30, Abstraction-Creátion; teniendo en cuenta que tanto la adhesión a la abstracción como su condición femenina eran dos filiaciones minoritarias en el contexto de las vanguardias artísticas de la época, nos proponemos explorar las intersecciones y confluencias entre ambas y sus implicaciones en la recepción y valoración de la obra de las artistas en cuestión.

\section{La abstracción en los años 30: de Art concret y Cercle et carré a Abstraction- Creátion}

En la segunda mitad de la década de los años 20 París se había convertido de nuevo en la capital de la vanguardia internacional, y la mayoría de artistas abstractos vivían o pasaban mucho tiempo allí; sin embargo, la abstracción continuaba siendo una tendencia artística minoritaria y con mucha menos presencia pública y comercial que otros movimientos, como el omnipresente Surrealismo, las variantes del postcubismo o las nuevas figuraciones de la Escuela de París. Por ello, ya a finales de los años 20 se habían lanzado algunas iniciativas que tenían como objetivo agrupar y promover a los artistas abstractos. Por una parte nos encontramos con Art concret, colectivo impulsado por Théo Van Doesburg en el que también participaron Tutundjan, Hélion, Carlsund y Wantz; Art concret tuvo una vida muy breve que sólo se concretó en la aparición de un número de la revista del mismo nombre en abril de 1930. Algo 484 
más sólido como grupo fue Cercle et carré, impulsado por Joaquín Torres-García y Michel Seuphor, que entre marzo y junio de 1930 publicó tres números de su revista homónima y organizó una exposición en la que tomaron parte cuarenta y seis artistas, entre los cuales Mondrian, Kandinsky, Arp, Léger, Le Corbusier o Ozenfant (Prat, 1980). Pese a sus esfuerzos, sin embargo, el éxito comercial y crítico del proyecto fue nulo, lo que desanimó en gran medida a sus participantes; Torres-García abandonó el grupo por discrepancias con la línea impulsada por Seuphor, y la enfermedad de este en otoño de 1930 supuso su final definitivo.

La situación de los artistas abstractos en el París de los primeros años de la década de los 30 no mejoró demasiado: las repercusiones económicas del crac del 29 (que en Europa se hicieron más patentes a partir de 1931) en el mercado del arte redujeron más si cabe las expectativas de venta de muchos de ellos (Ceysson, 1979: 18-19), y la coyuntura política de la década se fue decantando hacia un conservadurismo aún más hostil a las propuestas de la vanguardia en general, y de la abstracción en particular. Pese a ello cada vez más artistas, procedentes de países donde dicha hostilidad se concretaba progresivamente en represión como Rusia, Hungría, Austria y Alemania, emigraron a París. La necesidad de agruparse persistía, y por ello ya en 1931, y en gran medida de los restos de Art concret y Cercle et carré, nació un nuevo grupo, Abstraction-Création (Fabre y Nobis, 1978; Fabre, 1990: 89-103). La asociación se creó el 15 de febrero de 1931, y el primer comité director estuvo formado por Herbin, Van Doesburg (sustituido a su muerte por Vantongerloo), Hélion, Arp, Gleizes, Kupka, Tutundjan y Valmier (habría algunos cambios a lo largo de los años). Quince de sus primeros socios habían participado en Cercle et carré, y dos de los miembros del comité procedían de Art concret.

Intentando superar las diferencias que habían minado la existencia de los dos grupos anteriores y habían avivado su confrontación, Abstraction-Création propuso una concepción de la abstracción abierta a todas las tendencias, tanto a los que practicaban una abstracción geométrica o conceptual, como a aquellos que operaban partiendo de elementos figurativos. Como muestra de la voluntad de aceptación de la diversidad real que se daba en la práctica de los diversos artistas abstractos, en el prefacio al primer número el Comité director escribió lo siguiente (la traducción es de la autora): "Abstracción porque ciertos artistas han alcanzado la concepción de figuración mediante la abstracción progresiva de las formas de la naturaleza. Creación porque otros artistas han alcanzado directamente la no figuración por una concepción de orden puramente geométrico (...)" (abstraction création art non figuratif, $\mathrm{n}^{\mathrm{o}} 1$ : 1). Esta apertura, sin embargo, no evitaría los debates teóricos sobre la conceptualización de la abstracción iniciados ya con la misma elección del nombre del grupo, y que llevaron en 1934 a la defección de una parte de sus miembros, entre ellos Hans Arp y Sophie Taeuber, debido a que percibían un posicionamiento demasiado restrictivo en la dirección del mismo. Activo hasta 1936, el grupo publicó cinco números anuales de una revista titulada abstraction création art non figuratif, inició una línea de monografías de artistas (aunque sólo se publicaron las correspondientes a Herbin y al grupo de pintores suizos), y organizó varias exposiciones colectivas. En la revista participaron cerca de un centenar de artistas de distintas nacionalidades, y Abstraction-Creátion llegó a contar como «miembros y amigos» a unas cuatrocientas personas, la mitad de ellas residentes en París (acanf, $\mathrm{n}^{\circ} 4: 2$ ). Por lo que se refiere a 
las exposiciones, aunque según algunas fuentes ya en 1931 o 1932 el grupo organizó alguna muestra colectiva (Pagé y Billeter, 1989: 132; Léal, 2003: 167; Léal y Simon, 2009: 379), sería entre finales de 1933 y abril de 1935 (Fabre y Nobis, 1978: 13) cuando tuvo lugar una actividad más estable en un local que la asociación alquiló en la Av. de Wagram, 44. La primera muestra, anunciada como «exposición permanente», se inauguró el 22 de diciembre de 1933, y desde enero de 1934 la siguieron una serie de exposiciones colectivas e individuales de los miembros del grupo. Por el importante número de artistas que agrupó, por la relevancia de los mismos y por la dimensión internacional que consiguió, Abstraction-Création puede ser considerada la agrupación de artistas abstractos más importante de la década, y una de las más relevantes desde cualquier perspectiva.

Para comprender el desarrollo de Abstraction-Création es necesario tener en cuenta que, aun moviéndonos en un mismo contexto amplio de vanguardia, el arte creado en los años 30 tuvo un carácter fundamentalmente distinto al producido en las dos décadas anteriores. Frente al talante más utópico e incluso dogmático de éstas, el arte de los años 30 ha podido ser cualificado de post-vanguardista y sintético (Llorens, 1997: 27); la pintura abstracta parisina del momento se caracterizó por un énfasis en la libertad individual de los artistas que se materializó en el compromiso entre las corrientes geométricas y no geométricas, una nueva conciencia de la superficie que iba más allá del énfasis en el plano, y en general una mayor complejidad de las composiciones, que avanzaron incluso hasta la sensualidad (Elderfield, 1970-II). Por ello, y por lo que se refiere a los participantes en Abstraction-Création, se incidió más, como hemos apuntado, en los puntos de encuentro en la diversidad que en la definición estricta de los límites estéticos; ello permitió que el grupo acogiera a un gran número de artistas cuyas prácticas fueron mucho más allá de lo geométrico para abrazar también el biomorfismo, uno de los rasgos fundamentales del arte de la década (Fabre, 1997: 73-75; Clair, 2008: 18), como demuestra por ejemplo la evolución de Kandinsky. Incluso en el trabajo de aquellos artistas que se mantuvieron fieles a la abstracción geométrica, como Mondrian, puede percibirse como las composiciones se van complicando, lo que genera cierta ambigüedad en la hasta entonces prístina búsqueda del equilibrio en su pintura (Elderfield, 1970-I). Conceptos como la indeterminación, el azar, incluso el primitivismo, hasta ese momento completamente ajenos al discurso teórico de la abstracción y a su concreción artística, se fueron integrando en las nuevas prácticas del periodo, apuntando direcciones cuyo completo desarrollo no se revelaría hasta después de la Segunda Guerra Mundial (Fabre, 1997).

\section{Las mujeres artistas de Abstraction-Création}

El papel de las mujeres artistas en el contexto de Abstraction-Création puede entenderse mejor en comparación a su participación en los dos grupos que le precedieron. Así, mientras que en Art concret no encontramos a ninguna mujer, en Cercle et carré fueron diez las artistas que tomaron parte en la exposición (Ingibjoerg Bjarnason, Marcelle Cahn, Franciska Clausen, Nadia Chodasiewicz-Grabowska, Alexandra Exter, Vera Idelson, Nechama Smuszkowicz, Sophie Taeuber, Adya Van Rees y Wanda Wolska), a las que habría que sumar la publicación de una fotografía de Florence Henri en la revista. De ellas sólo una, Sophie Taeuber, se integraría después 
en Abstraction-Création; sabemos que Marcelle Cahn fue invitada por escrito por Otto Freundlich a tomar parte en el segundo número de la revista del nuevo grupo (en el archivo del Museo de arte moderno de Estrasburgo se conserva una copia de dicha carta), pero ella rechazó la oferta, en parte porque no intuyó la envergadura del proyecto (Cahn, 1972: 154), y en parte porque su pintura del momento tendía a la figuración (Prat, 1984:38). Teniendo en cuenta la estrecha relación entre ambos grupos a la que ya hemos hecho referencia, sin duda esta escasa continuidad en la participación de las mujeres resulta significativa, y más si nos fijamos en el hecho de que la trayectoria artística de la mayoría de las participantes en Cercle et carré, por distintos motivos, se ralentizó, se detuvo temporalmente o incluso finalizó definitivamente justo después de participar en el proyecto (Faxedas, 2015).

Así pues, las mujeres cuya obra estuvo presente en algún número de abstraction creátion art non figuratif fueron doce: Sonia Delaunay (1885-1979), Katherine Dreier (1877-1952), Laure Garcin (1896-1978), Barbara Hepworth (1903-1975), Evie Hone (1894-1955), Mainie Jellett (1897-1944), Katarzyna Kobro (1898-1951), Jeanne Kosnick-Kloss (1892-1966), Marlow Moss (1889-1958), Alexandra Povòrina (18851963), Sophie Taeuber (1889-1943) y Paule Vézelay (1892-1984). Algunas de ellas también mostraron su trabajo en varias de las exposiciones colectivas organizadas por el grupo: Garcin, Hepworth, Hone, Jellett, Kosnick-Kloss, Moss, Taeuber y Vézelay. En comparación con Cercle et carré, proporcionalmente la participación de mujeres en Abstraction-Creátion fue menor: aunque el segundo grupo tuvo el doble de miembros que el primero, el número de mujeres permaneció prácticamente idéntico. De ellas, sólo Sophie Taeuber asumió alguna responsabilidad organizativa: en 1934 fue miembro del comité de dirección, y fue la editora del citado libro de los cinco pintores suizos (que incluía su obra junto a la de Erni, Schiess, Seligmann y Vulliamy) (Stroeh, 1989: p. 132).

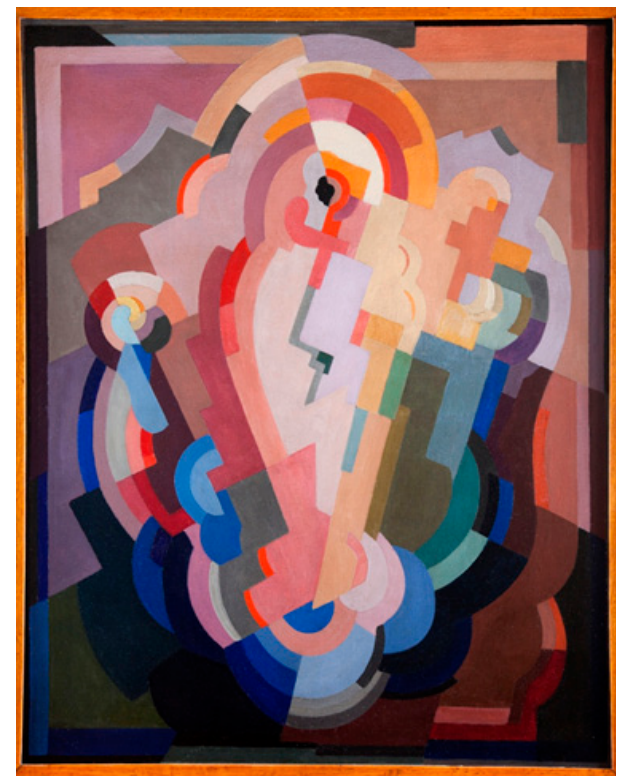

Figura 1. Mainie Jellett, Abstract composition, 1935 c. (Crawford Art Gallery, Cork). 
Estas doce mujeres forman un grupo mucho más heterogéneo que el de las integrantes de Cercle et carré, la mayoría de las cuales estaban relacionadas con la Académie Moderne de Léger y Ozenfant. De las participantes en AbstractionCréation, Delaunay, Hepworth, Kobro y Taeuber son artistas cuya obra ha sido progresivamente reconocida, tratada en monografias y exposiciones, y hasta cierto punto incorporada a los discursos contemporáneos sobre las vanguardias y la modernidad. Delaunay fue un miembro activo de la vanguardia artística europea desde principios de los años 10, tanto por su trabajo pictórico como por sus incursiones en el ámbito de las artes aplicadas (Robert, Sonia Delaunay, 1985); Taeuber también había practicado numerosas disciplinas artísticas (danza, pintura, bordados, collage, escultura,...), tanto en el contexto del dadaísmo como después en el de la abstracción (Pagé y Billeter, 1989). El trabajo escultórico de Hepworth, que exponía habitualmente en Inglaterra, se estaba moviendo también a principios de los años 30 hacia la abstracción, lo que pronto la convertiría en una de las figuras clave de las vanguardias británicas (Curtis, 1994). Por lo que se refiere a Kobro, aunque de origen ruso, era una de las figuras centrales de la vanguardia en Polonia, donde había participado en los grupos Blok, Praesens y a.r., y era también una de las responsables de la formación de la importante Colección internacional de arte moderno de Lodz (Stemmler, Stanislawski, Bois y Grzechca-Mohr, 1991).

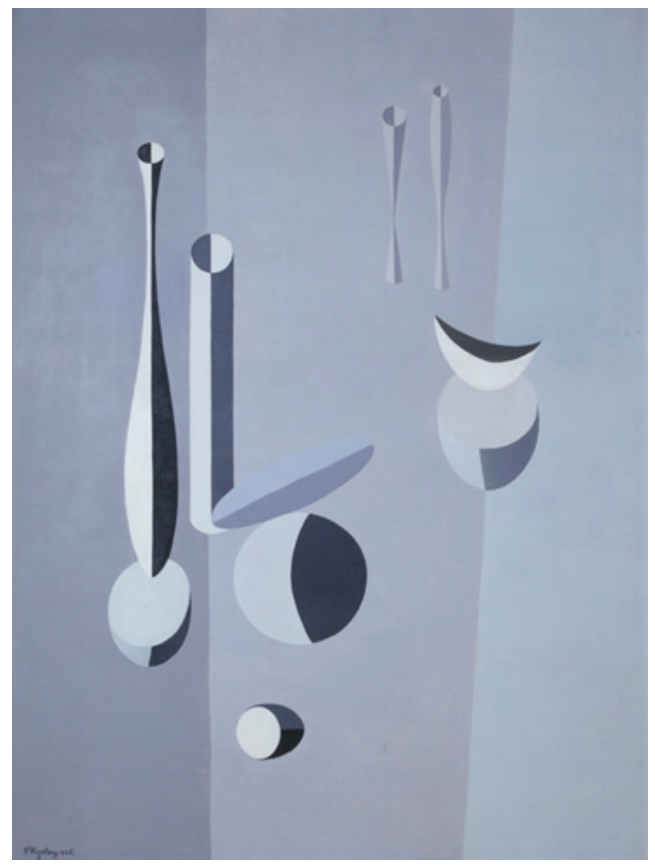

Figura 2. Paule Vézelay, Forms on Grey, 1935 @ Tate, London 2014.

Las demás artistas son, en su conjunto, menos conocidas para el gran público, pero casi todas han sido objeto de estudios más o menos pormenorizados. Las irlandesas Jellett y Hone fueron alumnas de Albert Gleizes en su taller de Puteaux desde 
1921, trabajando con él hasta entrados los años 30, y fueron invitadas a participar en Abstraction-Creátion por Auguste Herbin (Arnold, 1991: 131). Aunque la bibliografía suele referirse a ellas como un dúo que compartió prácticamente toda su trayectoria, es importante señalar que desde 1932 como mínimo sus respectivas obras siguieron caminos diferenciados: Hone se centró en los vitrales, y Jellett se convirtió en la figura de referencia del arte moderno en Irlanda [Fig. 1]. Dreier era una pintora norteamericana de origen alemán que viajó frecuentemente por Europa desde joven y que estableció contacto con la mayoría de artistas de vanguardia del continente, especialmente con Duchamp; a la larga sería más conocida por haber impulsado la Societé Anonyme (1920), un grupo que pretendía difundir y promover el estudio, coleccionismo y exhibición del arte moderno en los Estados Unidos (Herbert, Apter y Kenney, 1984). Vézelay y Moss eran dos artistas británicas que se habían instalado en París en 1926 y 1927, respectivamente; la obra de Vézelay estaba más cercana a las formas biomórficas de Arp [Fig. 2], mientras que la de Moss seguía y desarrollaba el neoplasticismo de De Stijl, siendo la primera en introducir la doble línea (en 1930), aunque en un sentido quizá distinto al de Mondrian. Moss estudió en la Académie Moderne en el curso 1928-29, momento en que empezó a hacer pintura no figurativa, y fue invitada a incorporarse a Abstraction-Création por Vantongerloo, a sugerencia de Mondrian (Howarth, 2008: 76). Vézelay, quién reclamaría para sí el haber sido la primera artista inglesa en practicar la abstracción antes incluso que Moore, Nicholson o Hepworth (Arnold, 1991: 132), fue invitada a Abstraction-Création por Hans Arp, a quién había conocido en 1928 (Pitts, 1980: 101). Curiosamente, ambas se llamaban Marjorie y adoptaron un pseudónimo para presentarse públicamente como artistas. Garcin era una artista francesa cuya obra de los años 30 se encontraba en un punto intermedio entre el surrealismo y la abstracción, optando por compaginar piezas más figurativas de carácter político, con otras más decididamente abstractas (Pertus, 1992); estuvo muy interesada en la reflexión estética y en otras formas artísticas como el cine. Alexandra Povòrina era una pintora de origen ruso que vivió en Alemania desde 1914, viajando frecuentemente a París; aunque gran parte de su obra se ha perdido, sabemos que desde finales de los años 20 su trabajo se acercó a la abstracción, y su obra fue decididamente abstracta entre 1930 y 1934 (Münster, 2003). A partir de esta fecha, debido a las progresivas dificultades para desarrollar su trabajo en la Alemania del momento, se dedicó más al diseño textil. Jeanne o Hannah Kosnick-Kloss era una cantante y pintora de origen alemán, instalada en Francia desde 1924, que aplicó también sus formas planas multicolores al arte del tapiz y el bordado [Fig. 3]; pareja de Otto Freundlich, quizá sea, de entre las participantes en Abstraction-Création, la artista cuya obra es menos conocida.

Las trayectorias de estas mujeres, nacidas entre 1877 y 1903, fueron muy diversas y no tendría sentido tratarlas de forma global; sin embargo, sí es importante señalar que todas ellas tuvieron unas carreras artísticas consistentes antes, durante y mayoritariamente después de tomar parte en Abstraction-Création. Cabe hacer notar que cinco de ellas (Delaunay, Hepworth, Kobro, Kosnick-Kloss y Taeuber) mantenían una relación de pareja con sendos hombres artistas que también participaron en el grupo, y que en todos los casos fueron miembros activos y destacados de las vanguardias artísticas del momento (el marido de Povòrina, Friedrich Ahlers- 
Hestermann, también era un pintor conocido pero no participó en los mismos círculos vanguardistas). Aunque sin duda el debate sobre las relaciones entre parejas en las que ambos miembros son artistas abre muchos interrogantes que no es mi propósito discutir aquí (Chadwick y De Courtivron, 1996), cabe señalar que en un momento tan complejo para el arte de vanguardia como el que nos ocupa, el hecho de formar parte de parejas con una presencia artística relevante pudo ser positivo para la proyección pública de estas mujeres, al menos en un primer momento. Así parece haberlo percibido la pintora Laure Garcin, quién en 1972 publicó en el catálogo de una exposición individual una lista de proyectos en preparación, uno de los cuales titulaba provisionalmente "La vie d'une femme sans protecteur (autobiographie)» (Garcin, 1972).

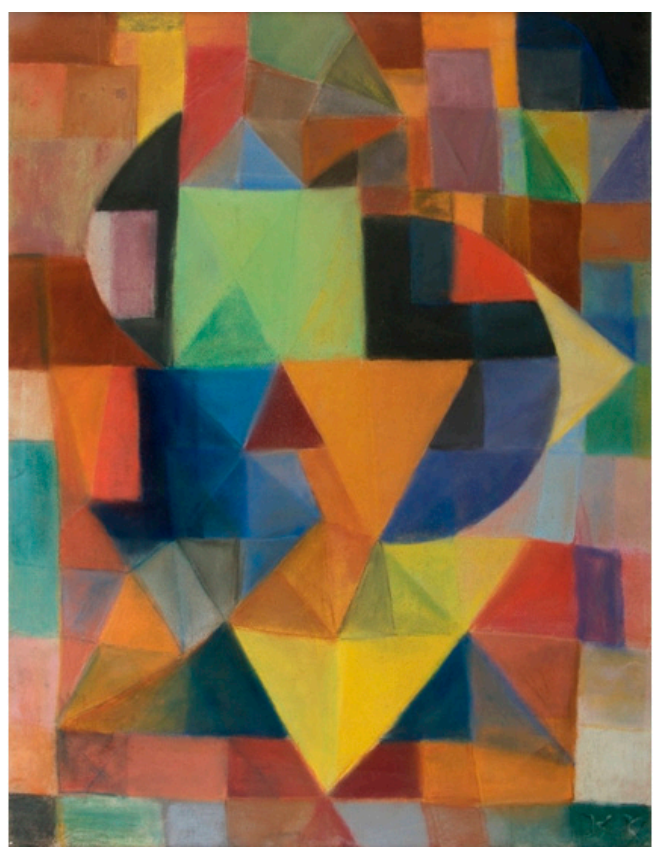

Figura 3. Jeanne Kosnick-Kloss, Composition, 1934 (Musée de Pontoise).

\section{La revista abstraction creátion art non figuratif (1932-1936)}

Lamentablemente, disponemos de muy poca información sobre las exposiciones organizadas por Abstraction-Creátion: no existen fotografías que nos permitan reconstruir los diversos montajes, ni catálogos que nos ayuden a documentar las obras presentadas en cada ocasión por los distintos artistas participantes. Teniendo en cuenta que como hemos comentado, la línea editorial de publicación de monografías no prosperó, el único legado sobre el que puede basarse nuestro estudio del grupo es pues la revista. En contraste con Cercle et carré, cuyo editor Michel Seuphor concedía una gran importancia al contenido teórico y procuró que este fuera considerablemente homogéneo (Valeri, 2013), la revista abstraction creátion art non 
figuratif (el título aparecía en la portada sin mayúsculas ni signos de puntuación) fue mucho más heterogénea, como el mismo Seuphor remarcaría posteriormente no sin cierta ironía (Seuphor, 1971: 24). Ciertamente, la idea original había sido otra: la asociación preveía publicar ocho números cada año que habrían contado con diversos artículos teóricos, críticos e históricos (Fabre, 1990: 103), pero la falta de medios económicos imposibilitó ejecutar dicho plan, y el número anual funcionó más bien como una especie de almanaque.

En su versión definitiva, cada número de la revista siguió la misma estructura: una portada sin ilustración en la que a la derecha aparecía en letras grandes el título de la revista, seguido del año de edición y el número; y a la izquierda, un listado por orden alfabético de todos los participantes en el número en cuestión. En la primera página se publicaba un editorial $\left(\mathrm{n}^{\mathrm{o}} 1\right.$ y 2$)$, o bien información sobre la asociación y sus actividades $\left(\mathrm{n}^{\circ} 3,4\right.$ y 5$)$; y seguidamente una serie de reproducciones de entre una y tres obras de cada artista representado, ordenadas más o menos alfabéticamente y acompañadas de un texto breve del propio artista o de alguien seleccionado por él mismo. Aunque la responsabilidad de la revista era del Comité director, cada número tuvo un editor: Hélion para el primero, Herbin para el segundo, Vantongerloo para el tercero, y él mismo y Béothy para el cuarto; el último número se consideró editado por el Comité en su conjunto (formado en ese momento por Herbin, Vantongerloo, Béothy, Gleizes y Gorin). El número de participantes en la revista experimentó una progresión en los tres primeros números (41, 53 y 58 artistas representados, respectivamente), para caer en los dos últimos (33 y 30 artistas).

La revista presentaba en su conjunto un aspecto moderno pero muy austero (todas las reproducciones, no siempre de gran calidad, fueron en blanco y negro); los artistas aparecían citados en la portada sólo por su apellido (excepto, por motivos desconocidos, en el caso de Barbara Hepworth en el $n^{\circ} 2$ ). En el interior también aparecía sólo el apellido de los artistas, excepto en el primer número en que el criterio fue más variable (en algunos casos aparece nombre y apellido, en otros sólo apellido, $\mathrm{y}$ en otros éste va acompañado de la inicial del nombre). La cuestión del nombre, y de lo que este nos revela u oculta acerca de la identidad del artista, es un tema crucial en el contexto de la abstracción porque tiene que ver con el discurso universalista, superador de las individualidades y subjetividades, que en general defendían los artistas participantes; no en vano, en su texto "Evolution" del n ${ }^{\circ} 4$ de la revista Georges Vantongerloo escribió (la traducción es de la autora): “'yo, me, mi' son signos de la vieja civilización. El anonimato será el signo de la nueva era" (acanf, $\mathrm{n}^{\circ}$ 4: 32). Esta ocultación de la identidad es especialmente significativa, como veremos, en el caso de las mujeres, porqué la neutralización del género mediante la omisión del nombre propio, así como el uso de pseudónimos de género indefinido (como los escogidos por Moss y Vézelay) ha sido una estrategia utilizada en diversas ocasiones por las mujeres artistas con el objetivo de evitar cualquier tipo de prejuicio respecto a su obra (Moulin, 1992: 282). En este sentido, puede que cuando Marlow Moss publicó el siguiente texto en el tercer número de la revista no se refiriera solamente a los prejuicios genéricos a los que se enfrentaba la abstracción en ese momento, sino que su género como artista fuera percibido también como algo que el espectador debía, de algún modo, superar (la traducción es de la autora): “.......para ayudar un poco al 
espectador profano le aconsejo mirar mi obra sin prejuicios......" (acanf, $\left.\mathrm{n}^{\circ} 3: 30\right)$.

En el primer número de la revista los editores invitaron a los artistas a expresar en un texto, escrito por ellos mismos o por alguien con quién sintieran alguna afinidad artística, "las razones que juzgan como motivación esencial de su actitud" (acanf, $\mathrm{n}^{\mathrm{o}}$ 1: 1) (la traducción es de la autora), concepto que se mantendría en los restantes números. El texto debía tener una extensión máxima de una página, algo que sin duda les limitaba, como expresó Jellett en una carta a Gleizes (Arnold, 1991; 132); sin embargo algunos artistas vinculados al Comité, como el mismo Gleizes, Hélion o Vantongerloo, escribieron textos mucho más largos. Si en el primer número la práctica totalidad de las reproducciones estuvo acompañada de un texto, en los siguientes cada vez es más frecuente que las reproducciones de las obras se publicaran sin ningún acompañamiento escrito. Aunque como hemos dicho algunos números contaron con textos teóricos más extensos, en ningún caso pueden ser considerados programáticos en el sentido en qué lo fueron los textos más importantes publicados en Cercle et carré; la única característica conjunta de los textos publicados en los distintos números es la diversidad de planteamientos, dentro de la defensa común de un concepto amplio de no-figuración. La intención de la revista era contar con una serie de firmas invitadas que evidenciaran la amplitud de miras de la asociación, y en este sentido debe interpretarse, por ejemplo, la publicación en el primer número de un texto de Seuphor, precisamente, e incluso del galerista Leónce Rosenberg, uno de los más favorables a la abstracción en el contexto comercial del París de la época.

\section{La participación de las mujeres artistas en la revista}

Si empezamos por un análisis cuantitativo de la participación de las mujeres, veremos que cuatro de ellas (por diez de sus compañeros masculinos) tomaron parte en los cinco números de la revista. En el primero Garcin sólo publicó un texto teórico, y en los demás imagen y texto, mientras que Moss publicó imágenes en todos, sin texto en los dos últimos números; sus aportaciones escritas en los tres primeros números son sus únicas declaraciones teóricas publicadas a lo largo de su carrera. Hone publicó texto e imagen en el primer número, y sólo imágenes en los siguientes, y Jellett imagen y texto en los tres primeros números, y sólo imágenes en los otros dos. Katherine Dreier participó en cuatro números ( $\mathrm{n}^{\circ} 1,2,3$ y 5$)$, con texto sólo en el segundo; con tres participaciones tenemos a Taeuber $\left(\mathrm{n}^{\mathrm{o}} 1,2\right.$ y 3 , con un texto de Seuphor acompañando sus dos imágenes del primer número) y Kobro $\left(\mathrm{n}^{\circ} 2,4\right.$ y 5 , con texto en el segundo número). Con dos participaciones encontramos a KosnickKloss ( $\mathrm{n}^{\circ} 2$ y 3 , imágenes y texto), Povòrina ( $\mathrm{n}^{\circ} 2$ y 4 , imágenes y texto) y Hepworth $\left(\mathrm{n}^{\mathrm{o}} 2\right.$ y 3 , imágenes y texto sólo en el primero). Y con una a Sonia Delaunay, quién sólo publicó en el primer número dos imágenes y un texto (a su marido Robert lo encontramos en los tres primeros números) y Vézelay $\left(\mathrm{n}^{\mathrm{o}} 3\right.$, imagen y texto).

Excepto Taeuber, pues, todas las artistas publicaron al menos un texto propio en la revista, lo que se vio facilitado porque el formato elegido hacía posible que las mujeres publicaran textos teóricos exactamente en las mismas condiciones que sus compañeros masculinos, sin encargos ni edición previas. Ello contrasta especialmente con Cercle et carré, puesto que en este caso, si hasta diez mujeres tomaron parte en la exposición, sólo dos llegaron a publicar algún texto en la revista. Este hecho por 
si sólo es muy destacable, ya que como ha sido señalado (Faxedas, 2013: 33-37; Gonnard y Lebovici, 2007: 147) es sin duda en el campo teórico donde se produjo el mayor desajuste entre las aportaciones de hombres y mujeres a la historia de las primeras décadas de la abstracción, como demuestra claramente el caso de Cercle et carré (Faxedas, 2015). Como sabemos, la dimensión teórica de los debates sobre la abstracción fue fundamental para su desarrollo, como quedó plasmado en los numerosos textos y artículos publicados por sus protagonistas, así como en la correspondencia y las relaciones que intercambiaron entre sí. Sin embargo, aunque un buen número de mujeres se adhirieron a la práctica de la abstracción ya desde los años 20 (Seuphor, 1957: 69), sus contribuciones teóricas a los debates sobre la misma fueron mínimas.

En este sentido, cabe señalar que alguna de las participantes en AbstractionCréation destaca precisamente por haber sido de las pocas mujeres cuyas aportaciones a la teoría del arte abstracto han sido consideradas relevantes; es el caso de Katarzyna Kobro, quién publicó en colaboración con Wladislaw Strzeminski el libro La composición del espacio. Los cálculos del ritmo espacio-temporal (1931), y en solitario artículos como "Funcionalismo" (1936), que apareció en el no 4 de la revista Forma (Strzeminski y Kobro, 1977). Aunque se trata de textos que en su momento tuvieron relativamente poca difusión, la teoría sobre la escultura que ambos artistas desarrollaron (conocida como "unismo") ha sido considerada como una de las más elaboradas del siglo XX (Bois, 1993: 144). La obra teórica de otras artistas del grupo no llegó a ser tan consistente; los dos únicos textos publicados por Sophie Taeuber, por ejemplo, son sendos escritos dedicados a la enseñanza de las artes ornamentales que aparecieron en 1922 y 1927 (Taeuber, 2009a y 2009b); y aunque entre 1937 y 1939 fue la editora de la revista Plastique/Plastic, no publicó en ella ni un solo artículo teórico. Paule Vézelay, por su parte, publicó algunos artículos en diversas publicaciones sobre la vida artística parisina (1922) o sobre Juan Gris (1928) (Alley, 1983: 10). Sonia Delaunay también publicó algunos textos en la prensa entre 1932 y 1934 sobre la relación entre arte y artes aplicadas, pero no desarrolló una obra propiamente teórica. En su autobiografía ella misma afirma que Robert tenía una actitud más intelectual que ella, "mucho más científica si se quiere, porqué él no buscaba la explicación sino la justificación de sus teorías" (Delaunay, 1978: 108) (la traducción es de la autora); y en general siempre insistió en que sus propias investigaciones "nunca eran teóricas, sino basadas solamente en la sensibilidad" (Delaunay, 1967: 15) (la traducción es de la autora).

De entre los textos publicados por las mujeres en la revista, ocupa un lugar singular el de Laure Garcin en el primer número, uno de los cuatro artículos teóricos escritos por firmas invitadas que se incluyeron. No sabemos con precisión como entró en contacto Garcin con los impulsores del grupo, ni porque se le pidió justamente a ella el texto en cuestión, sobre todo teniendo en cuenta que los demás autores de estos textos (Seuphor, Rosenberg y Paul Vienney) eran mucho más conocidos y reputados que ella en el mundo artístico de París en general, y en el de la abstracción en particular. De hecho las primeras telas propiamente abstractas no las pintó Garcin hasta 1932, siendo las de 1931 todavía de estilo cubista (Pertus, 1992: 16). Es posible que Garcin entrara en contacto con el grupo mediante su participación en el salón "1940” (1931), 
donde también expusieron muchos de los miembros del mismo. Como expresaría ella misma más tarde en un manuscrito inédito, participar en Abstraction-Création fue una forma de comprometerse también socialmente (la traducción es de la autora):

Nuestros cuadernos aparecieron en el momento que yo llamo la época heroica del arte no figurativo. Un combate temerario que no podía explotarse comercialmente, puesto que éramos injuriados por la crítica oficial y sus lectores y sistemáticamente rechazados por todos los salones oficiales. (citado en Pertus, 1996: 17).

De hecho en su texto habla de la relación entre el arte abstracto y el desarrollo social, que a su juicio se concreta en el hecho de que el arte estimula el espíritu, con lo que concuerda con las nuevas necesidades del ser humano (acanf, $\mathrm{n}^{\circ}$ 1: 47).

Por lo que se refiere a los materiales que se fueron publicando en los demás números, cabe recordar que, como hemos indicado, la nota dominante en AbstractionCreátion fue la heterogeneidad entre las posiciones y obras de los diversos artistas participantes, por lo que no es posible definir una línea teórica clara y dominante. Aunque ciertamente el comité director intentó delimitar una cierta definición de la abstracción (expresada en la selección de los artistas que podían participar o de las obras que presentaban, que en ocasiones fueron descartadas por demasiado figurativas), lo cierto es que al hojear la revista se observa fácilmente la diversidad que va de la abstracción geométrica a las formas biomórficas, próximas al surrealismo. Lo mismo sucede con los textos teóricos, que incluyen declaraciones muy afines al espíritu neoplástico, pero también manifestaciones más abiertas, especialmente en los textos del segundo número que debían responder a unas cuestiones planteadas por el comité.

De entre las aportaciones teóricas de las mujeres artistas, que como ya hemos dicho comparten esta heterogeneidad, destacamos algunos elementos interesantes. En todos sus textos Garcin mantiene su defensa del valor social y colectivo del arte abstracto (como Gorin o Herbin en los suyos por ejemplo, y radicalmente al contrario que Vienney en el primer número), aun argumentando que la verdadera cuestión plástica no es la de ser o no figurativo, sino la de saber mantener el equilibrio entre los distintos elementos que constituyen la obra (acanf, $\mathrm{n}^{\circ} 2$ : 17). Povòrina apuesta por el valor espiritual del arte y se remite a los procesos creativos de la naturaleza como modelo para su propio trabajo (acanf, $\mathrm{n}^{\circ}$ 2: 35); así mismo, Dreier también comparte la idea del árbol como símbolo del arte, que surge de la tierra y se acerca el cielo, haciendo hincapié en una visión internacional (acanf, $\mathrm{n}^{\circ} 2$ : 10). Kosnick-Kloss insiste en el elemento subjetivo que aporta a la obra el espectador (acanf, $\left.\mathrm{n}^{\mathrm{0}} 3: 27\right)$; y en su breve aportación Vézelay apela a la subjetividad, en su caso, del artista, capaz de expresar mediante la línea sus propias visiones (acanf, $\mathrm{n}^{\circ} 3$ : 48). De forma muy coherente con su propio trabajo del momento, Delaunay reivindica el retorno al orden que se expresa en el arte actual, ya que después de la destrucción cubista se aprecia una voluntad de "participar en la reconstrucción de un mundo nuevo: ordenado, claro, sano, generoso, optimista y dinámico" (acanf, $\mathrm{n}^{\circ}$ 1: 8) (la traducción es de la autora).

Las aportaciones de Moss comparten plenamente el ideario y el vocabulario neoplásticos, en la línea de su maestro Mondrian; así, en el primer número manifiesta que "la tarea del hombre es pues la de profundizar en su conciencia del universo a 
fin de poder establecer el equilibrio de relaciones que debe existir mutuamente entre sus formas visibles e invisibles" (acanf, $\mathrm{n}^{\circ} 1: 26$ ) (la traducción es de la autora), y en el segundo declara a la naturaleza la mayor enemiga del hombre, por lo que la nueva plástica no figurativa se hace imprescindible (acanf, $\mathrm{n}^{\circ} 2: 29$ ). Jellett se encontraba en las antípodas de esta posición; en una carta a Gleizes escribió lo siguiente sobre el segundo número de la revista:

No puedo decir que me sienta muy entusiasmada por él, con algunas excepciones pienso que el trabajo es muy pobre y vacio - (...) Odio las curvas y giros de Herbin, me gustan bastantePowery Valmier, Reth, Garcinyalgo delaescultura,peronomeimportanenabsoluto todos los seguidores de Mondrian. (Arnold, 1991: p. 137) (la traducción es de la autora).

En sus propios textos insistió en la idea de que la pintura debía ser capaz de generar alguna emoción en el espectador, basándose en su armonía, ritmo y composición (acanf, $\left.\mathrm{n}^{\mathrm{o}} 1: 22\right)$. Hone remite esta capacidad emocional de arte abstracto al antiguo arte de los celtas, quiénes también disfrutaban sólo de las realidades de la forma y el color (acanf, $\mathrm{n}^{\circ}$ 1:20). En un texto largo Hepworth reflexiona sobre las relaciones entre arte abstracto y música, un tema que Jellett también había introducido, y que es sin duda uno de los leitmotivs de la abstracción (acanf, $\mathrm{n}^{\circ}$ 2: 6). Quizá el texto más sugerente lo ofrece Kobro, quién respondiendo a la curiosa pregunta planteada por los editores del $\mathrm{n}^{\circ} 2$ de la revista (“¿Porque no pinta usted desnudos?", acanf, $\mathrm{n}^{\circ} 2: 1$ ), responde lo siguiente: "La acción de esculpir un desnudo proporciona unas emociones de orden fisiológico o sexual. Yo hago escultura a partir de un modelo como quién va al cine para descansar mejor" (acanf, $\mathrm{n}^{\circ}$ 2: 27) (la traducción es de la autora). Es decir, una de las más importantes escultoras abstractas de su generación admite esculpir desnudos figurativos, como efectivamente hizo hacia 1925 (Stemmler et al., 1991), y contrapone el carácter erótico y sensual de los mismos a su trabajo abstracto.

\section{Después de Abstraction-Création}

A diferencia de lo sucedido con sus colegas de grupos anteriores, la participación en Abstraction-Création puede ser considerada en general como una fase positiva en la evolución profesional y artística de estas mujeres, la mayoría de las cuales siguieron desarrollando sus trayectorias, celebrando exposiciones individuales y participando en otros grupos, exposiciones y salones diversos. Sin ánimo exhaustivo, señalamos que muchas de ellas tomarían parte en una o varias ediciones del Salon des realités nouvelles, el siguiente gran acontecimiento que tuvo lugar en Francia relacionado con la abstracción a partir de 1939: Delaunay (una de sus impulsoras), Hepworth, Kosnick-Kloss, Moss, Taeuber y Vézelay. Taeuber participó en la importante exposición Thèse antithèse synthèse (Lucerna, 1935), y junto a Moss también expuso en Konstruktiven (Basilea, 1937). En 1938 Hepworth, Kosnick-Kloss, Moss, Taeuber y Vezélay expusieron en Tentoonstellinq Abstracte Kunst (Ámsterdam, 1938). A través de la edición de la revista Plastic/Plastique (1937-39) Taeuber sería quien daría continuidad a la labor del grupo, estableciendo puentes con la reciente y cada vez más activa escena artística norteamericana.

Hepworth fue en Londres un miembro activo del grupo Unit One (1934) e impulsó el almanaque Circle (1937); Jellett y Hone, por su parte, realizarían una importante 
tarea de difusión del arte moderno en Irlanda. En 1953 Vezélay fundaría en Londres el Group Espace como subsidiario de su homólogo europeo (Fowler, 2007). Kobro seguiría desarrollando su trabajo en los años 30 en Polonia en la medida en que la situación socio-política lo hizo posible; participó en la revista Forma y firmó el Manifiesto dimensionista (1937) impulsado por Arp, Duchamp y Moholy-Nagy. Garcin, que había participado también en la Association des Artistes et Écrivains Révolutionnaires, dejó ambos grupos para centrarse en sus estudios teóricos, y más tarde en el cine de animación. Povòrina desarrolló su carrera en Alemania, cada vez con mayores dificultades debido a la situación política. Algunas de ellas se dedicaron también a la pintura mural, que tuvo un papel muy relevante en los años 30 debido a su carácter público y por lo tanto a su connotación social. Sonia Delaunay, para quién la participación en Abstraction-Création coincidió con su vuelta a la práctica de la pintura abstracta después de años de dedicarse a las artes aplicadas, participó en los Salons d'art mural; y junto a su marido Robert, dirigió las pinturas murales de dos pabellones de la Exposición internacional de artes y técnicas de París de 1937. Jellett fue la responsable de los murales en los pabellones irlandeses de las exposiciones de Glasgow (1938) y Nueva York (1939) (White, 1962).

\section{Conclusiones}

En el primer número de abstraction création art non figuratif el pintor Jean Gorin escribió lo siguiente: "el hombre se desprende finalmente de todo sentimentalismo, de todo particularismo (...) un arte puro, colectivo, universal y científico ha nacido (...) es el arte impersonal por excelencia" (acanf, $\mathrm{n}^{\circ} 1: 16$ ) (la traducción es de la autora). En su texto (póstumo) para el mismo número Van Doesburg insistía en qué "debemos suprimir nuestra personalidad sin duda alguna, el universal está por encima de la misma" (acanf, $\mathrm{n}^{\circ}$ 1: 39) (la traducción es de la autora). Ambos autores apelan pues a un universalismo compartido por muchos de los miembros del grupo que comportaría necesariamente la superación inmediata de toda certeza identitaria, así como de los individualismos, personalismos y fronteras (Michaud, 1997: 23). Por ello el segundo número de la revista incluía una editorial en la que se afirmaba que "toda tentativa de limitar los esfuerzos artísticos según consideraciones de raza,

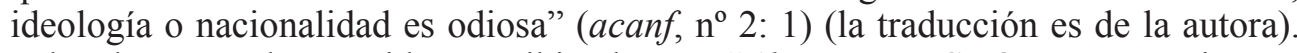
Fabre ha apoyado esta idea escribiendo que "Abstraction-Creátion promocionó a jóvenes artistas de todas las nacionalidades y favoreció numerosas renovaciones artísticas extranjeras", manteniendo "(...) una voluntad muy firme de preservar la expresión individual de cada artista no figurativo, sin censura extra pictórica debida a su ideología, raza o nacionalidad" (1978: 15) (la traducción es de la autora). En una década dominada por la ideología del hombre nuevo (Clair, 2008), sin embargo, la aceptación de la pluralidad no parece haber incluido la diversidad de género, ya que ninguno de los recurrentes debates y llamadas a la universalidad tuvo en cuenta las particularidades del mismo. La historiadora del arte Griselda Pollock ha sintetizado perfectamente la cuestión de cómo la modernidad convirtió en irrelevante el debate sobre la identidad del artista, en particular por lo que se refiere a su género (la traducción es de la autora): "en la búsqueda de verdades universales, valores 
absolutos y pureza estética, el género y todas las demás formas de posicionamiento social fueron considerados irrelevantes" (1996: 67).

En parte porque nos situamos en una década en qué la situación política y social acaparó la mayor parte del activismo artístico, y en parte por las mismas características de la modernidad (Felski, 1995), toda posibilidad de considerar la diferencia femenina como un elemento significativo quedó anulada; al contrario, y de nuevo en palabras de Pollock, a las mujeres de las vanguardias, "para conseguir el acceso a su máxima humanidad, no se les permitió nada de su feminidad" (1996: 69). El arte podía ser universal en la medida en qué no quedara contaminado por ningún atisbo de feminidad; quizá por ello las mujeres evitan cuidadosamente toda referencia a cualquier cuestión que tuviera alguna connotación de género tanto en sus obras como en sus textos para la revista (con la posible excepción de Kobro, ya citada). La ocultación de los nombres propios o el uso de pseudónimos, al que ya hemos aludido, participan de la misma lógica; y es coherente con ella que la encuesta sobre el número y nacionalidad de los simpatizantes del grupo que apareció en el $\mathrm{n}^{\mathrm{o}} 4$ de la revista tampoco tuviera en cuenta la dimensión de género. Resulta cruelmente irónico, en este sentido, que el único texto publicado en abstraction creátion art non figuratif que alude clara y directamente a la diferencia de género sea el que escribió Michel Seuphor para acompañar la obra de Sophie Taeuber, en el que leemos:

El hombre trabaja en la linde del bosque dónde, con una sonrisa y sin cansarse, tala los árboles numeros y caducados (góticos) que nos impiden ver la claridad blanca del día. (...) el destino de la mujer no contiene estas vastas empresas ni estas conquistas: el plan social en ellas se limita a sus hijos. (acanf, $\mathrm{n}^{\mathrm{o}} 1: 36$ ) (la traducción es de la autora).

El hecho de que estos "hijos" puedan ser una metáfora de sus obras no esconde la dureza del juicio. No está de más recordar que, aunque ciertamente en la Francia de los años 30 existía una imagen consolidada de la mujer artista moderna y profesional, el concepto imperante de feminidad se fue haciendo más conservador y reaccionario respecto a la visión relativamente más abierta que había imperado en los años 20 (Birnbaum, 2011: 17-18). La crisis económica facilitó la promoción de una idea de la mujer más doméstica, ligada a la maternidad y las tareas del hogar, lo que sin duda no contribuyó a facilitar su integración en un sistema del arte que nunca las había recibido cordialmente.

Sin embargo, y pese a todo ello, las mujeres parecen haberse integrado más cómodamente en Abstraction-Création que en grupos anteriores, como demostraría su presencia igualitaria en la revista así como su participación en las exposiciones del grupo (Fabre y Nobis, 1978: 302-303). Y sin duda, para todos los miembros del mismo la participación en el mismo supuso tomar parte en un espacio de debate y confrontación de sus respectivos trabajos muy significativo, lo que fue especialmente relevante para aquellas artistas que tenían pocos contactos o se movían en círculos muy reducidos, como Garcin, Hone o Jellett. Así mismo, creo que no hay duda que el paso de la intransigencia del período heroico de las vanguardias en el que aún se incluía el grupo liderado por Seuphor y Torres-García al hecho de que AbstractionCréation surgiera en un contexto post-vanguardista jugó en este caso a favor de las mujeres. El discurso teórico de la abstracción, como ejemplifica Cercle et carré, se 
había fundado en un dualismo en qué lo masculino se asoció al espacio privilegiado de lo intelectual, racional y espiritual, y lo femenino al más devaluado de lo material, sentimental e intuitivo; y pese a que hablamos, en principio, de conceptos abstractos, existe cierta relación entre esta consideración de lo femenino y una visión negativa de las mujeres y su trabajo (Danto, 1995: 68). Que este dualismo de los años 20 fuera sustituido por una opción de síntesis en los años 30 sin duda contribuyó a que las mujeres y sus creaciones se situaran en un espacio más confortable.

La heterogeneidad teórica y plástica como una de las características clave del trabajo del grupo también es significativa. Pese a la diatriba antisurrealista de Seuphor publicada en el primer número de la revista (acanf, $\mathrm{n}^{\circ} 1$ : 11) es evidente que ésta acogió a numerosos artistas cuya obra escapaba de los límites de la abstracción geométrica e incluso lírica para acercarse sin pudor al surrealismo en un sincretismo que, encabezado por Arp (y practicado también por Miró o Klee, por ejemplo, entre los no asociados al grupo), se convertiría en una de las propuestas artísticas más importantes de los años 30. Podemos decir pues que el vocabulario plástico de formas biomórficas y orgánicas desarrollado por algunos artistas del grupo "contradice la geometría por su libertad, su flexibilidad, su suavidad" y connota "el anti-orden, la anti-racionalidad, lo indeterminado en general o más específicamente, lo femenino, lo vegetal, lo biológico, la corporalidad, la intuición, lo inconsciente" (Fabre, 1997: 74) (la traducción es de la autora). Sin duda esta asociación entre determinadas formas y lo femenino es problemática, y desde luego no se corresponde con el tipo de obra que creaban mujeres y hombres respectivamente (como demuestran las obras de Moss y Arp, por ejemplo). Pero sin duda la gran diversidad plástica que vemos plasmada en las páginas de la revista abstraction creátion art non figuratif contribuyó a diluir cualquier valoración artística que pudiera basarse en distinción de género alguna.

Las trayectorias de las artistas del grupo con posterioridad a su participación en Abstraction-Création sugieren, como hemos dicho, que la experiencia fue globalmente positiva para ellas. Aunque sin duda ser una artista vinculada al arte abstracto en el París de los años 30 suponía una experiencia particularmente contradictoria en muchos aspectos, parece claro que poco a poco las mujeres consiguieron ocupar un espacio propio en el contexto del arte de vanguardia, aunque éste fuera, a menudo, incómodo e inestable, y se consiguiera a costa de obviar la propia identidad. En este sentido no hay duda de que el carácter más sintético, mixto e impuro del arte de los años 30 respecto a la década anterior muestra que es precisamente cuando aparecen las fisuras de la modernidad que las mujeres consiguen abrir espacios e incluso dar a conocer su propia voz.

\section{Referencias}

Les tendances nouvelles (Ed.). (1932-1923) abstraction création art non figuratif (acanf).

Alley, R. (1983). Paule Vézelay. Londres: The Tate Gallery.

Arnold, B. (1991). Mainie Jellett and the modern movement in Ireland. New Haven y Londres: Yale University Press.

Baumhof, A. (1999) "Las mujeres de la Bauhaus: un mito de la emancipación", en Fiedler, J. y Feierabend, P. Bauhaus (pp. 97-107). Colonia: Könemann. 
Birnbaum, P. (2011). Women artists in Interwar France. Framing femininities. Surrey y Burlington: Ashgate Pub. Co.

Bois, Y.-A. (1993). Painting as model. Cambridge, Ms.: The MIT Press.

Bowlt, J. y Drutt, M. (2000). Amazonas de la vanguardia: Alexandra Exter, Natalia Goncharova, Liubov Popova, Olga Rozanova, Varvara Stepanova y Nadezhda Udaltsova. Bilbao: Museo Guggenheim.

Cahn, M. (1972). Autobiographie. En Marcelle Cahn (p. 149-155). Saint-Étienne: [s.n.].

Ceysson, B. (1979). Peindre, sculpter, dans les années 30 en France. En L'art dans les années 30 en France (p. 13-31). Saint-Etienne: Musée d'art et industrie de Saint-Etienne.

Chadwick, W. (1985). Women Artists and the Surrealist Movement. London: Thames and Hudson.

Chadwick, W. y De Courtivron, I. (1996). Significant others: creativity \& intimate partnership. New York: Thames and Hudson.

Clair, J. (2008). La masse et la puissance. L'àge des dictatures. De l'homme sans qualités au travailleur. En Clair, J. (dir.). Les Annés 30: la fabrique de "l’homme nouveau” (p. 16-26). París [etc.]: Gallimard [etc.]

Curtis, P. (ed.) (1994). Barbara Hepworth: a retrospective. Liverpool: Tate Gallery, 1994.

Danto, A.C. (1995). After the end of art. Contemporary art and the pale of history. Princeton: Princeton University Press.

Delaunay, S. (1978). Nous irons jusqu'au soleil. París: Eds. Laffont.

Delaunay, S. (1967). Sonia Delaunay. En Sonia Delaunay (p. 13-15). París: MAM.

Elderfield, J. (1970). Geometric abstract painting and Paris in the thirties (partes I y II). Art Forum, mayo de 1970, $54-58$ y junio de 1970, 70-75.

Fabre, G. y Nobis, N. (1978). Abstraction-Création 1931-1936. Münster y París: Westfälisches Landesmuseum für Kunst und Kulturgeschichte Münster / Musée d'Art Moderne de la Ville de Paris.

Fabre, G. (1990). París 1930: arte abstracto, arte concreto, Cercle et Carré. Valencia: IVAM.

Fabre, G. (1997). L'art abstrait-concret à la recherche d'une synthèse. En Pagé, S. (ed.). Annés 30 en Europe. Le Temps menaçant, 1929-1939 (p. 71-75). París: Paris Musées y Flammarion.

Faxedas, Ll. (2013). Against Themselves? Women Artists in the Origins of Abstract Art. Brac:Barcelona, Research, Art, Creation, 1 (1), 2761. doi: 10.4471/ brac.2013.02.

Faxedas, Ll. (2015). Abstraction, gender and modernity: women artists of "Cercle et carré". En Woman's Art Journal, primavera de 2015 (en proceso de publicación)

Felski, R. (1995). The gender of modernity. Cambridge: Harvard Univ. Press.

Fowler, A. (2007). A Forgotten British Constructivist Group: The London Branch of Groupe Espace, 1953-59. The Burlington Magazine, Vol. 149, No. 1248, 173-179.

Garcin, L. (1972). Peintures récentes (recherches des structures dans lesquelles existe a l'état virtuel le dynamisme des métamorphoses). París: Galerie 9. 
Gonnard, C. y Lebovici, E. (2007). Femmes artistes / artistes femmes. Paris, de 1880 à nos jours. París: Hazan.

Hemus, R. (2009). Dada's women. London y New Haven: Yale University Press.

Herbert, R., Apter, E. y Kenney, E. (eds.) (1984). The Societé Anonyme and the Dreier Bequest at Yale University. A Catalogue Raisonné. New Haven y London: Yale Univ. Press.

Howarth, L. (2008). Marlow Moss (1889-1958). Tesis doctoral presentada en la University of Plymouth. Recuperada el 26 de agosto de 2014 desde http://pearl. plymouth.ac.uk/handle/10026.1/831

Léal, B. (dir.) (2003). La donation Sonia et Charles Delaunay dans les collections du Centre Georges Pompidou / Musée National d'Art Moderne. París: Centre Gerges Pompidou.

Léal, B, y Simon, J. (2009). Alexander Calder: les années parisiens, 1926-1933. Nueva York y París: Whitney Museum of American Art y Centre Georges Pompidou.

Llorens, T. (1997). Le mouvement moderne au moment de la synthèse. En Pagé, S. (ed.). Annés 30 en Europe. Le Temps menaçant, 1929-1939 (p. 26-29). París: Paris Musées y Flammarion.

Michaud, E. (1997). Nationalisme et internationalisme. En Pagé, S. (ed.). Annés 30 en Europe. Le Temps menaçant, 1929-1939 (p. 23-25). París: Paris Musées y Flammarion.

Moulin, R. (1992). L'artiste, l'institution et le marché. París: Flammarion.

Müller, U. (2009). Bauhaus women. Art, Handicraft, Design. París: Flammarion.

Münster, A. (2003). "Kunst ist Spiel und tiefer Ernst". Die Imaginistin Alexandra Povòrina (1885-1963). Leben und werk. Tesis doctoral presentada en la JustusLiebig-Universität Giessen. Recuperada el 26 de agosto de 2014 desde http://geb. uni-giessen.de/geb/volltexte/2004/1585/

Pagé, S. y Billeter, E. (1989). Sophie Taeuber. París: Musée d'art moderne de la Ville de Paris.

Perry, G. (1995). Women artists and the Parisian avant-garde: modernism and feminine art, 1900 to the late 20's. New York: Manchester University Press.

Pertus, I. (coord.) (1992). Laure Garcin. Commune de Greoux-les Bains.

Pitts Rembert, V. (1980). Paule Vezélay's lines in space and other works. Arts magazine, noviembre de 1980, vol. 55, nº 3, 98-103.

Plastique/plastic, 1937-39 (1969). Reedición. Nueva York: Arno Press.

Pollock, G. (1996). Inscriptions in the feminine. En Catherine de Zeegher (ed.). Inside the visible: an elliptical traverse of 20th century art. In, of and from the feminine (p. 67-87). Boston (etc.): The Institute of Contemporary Art (etc.).

Prat, M.A. (1984). Peinture et avant-garde au seuil des annés 30. Lausanne: L'Age d'Homme.

Robert, Sonia Delaunay. (1985). París: Musée d'art moderne de la Ville de Paris.

Rosemont, P. (ed.) (1998). Surrealist Women. An International anthology. Austin: Univ. of Texas Press.

Seuphor, M. (1957). Dictionnaire de la peinture abstraite. París: F. Hazan.

Seuphor, M. (ed.) (1971). Cercle et carré. París: Pierre Belfond. 
Stroeh, G. (1989). Biographie. En Sophie Taeuber (p. 123-135). París: Musée d'art moderne de la Ville de Paris.

Stemmler, D., Stanislawski, R., Bois, Y.-A., y Grzechca-Mohr, U. (1991). Katarzyna Kobro, 1898-1951. Mönchengladbach: Städtisches Museum Abteiberg.

Strzeminski, W. y Kobro, K. (1977). L'espace uniste. Écrits du constructivisme polonais. Lausanne: L'Age d'Homme.

Taeuber-Arp, S. (2009a). Observaciones sobre la enseñanza del diseño ornamental. En Estrella De Diego (ed.). Sophie Taeuber-Arp. Caminos de vanguardia (p. 162165). Málaga: Museo Picasso.

Taeuber-Arp, S. (2009b). Guía para la enseñana del dibujo en las profesiones textiles. En Estrella De Diego (ed.). Sophie Taeuber-Arp. Caminos de vanguardia (p. 166173). Málaga: Museo Picasso.

Valeri, L. (2013). Seuphor as Editor: The Pursuit of a Unified Philosophy in Cercle et Carré's Journals. En Cercle et Carré and the International Spirit of Abstract Art (p. 56-71). Georgia: Georgia Museum of Art.

White, J. y McCarville, E. (1962). Mainie Jellet, 1897-1944. A retrospective exhibiton of painting and drawing. Dublín: Municipal Gallery of Modern Art.

Wismer, B. (ed.) (1995). Karo-Dame. Konstructive, Konkrete und Radikale Kunst von Freuen von 1914 bis heute. Aarau y Baden: Aargauer Kunsthaus y Verlag Lars Müller. 